\title{
Quality of care and client willingness to pay for family planning services at Marie Stopes International in Burkina Faso
}

\author{
Placide Tapsoba \\ Population Council \\ Dalomi Bahan \\ Emily Forsyth Queen \\ Gisele Kaboré \\ Population Council \\ Sally Hughes
}

Follow this and additional works at: https://knowledgecommons.popcouncil.org/departments_sbsr-rh

Part of the Demography, Population, and Ecology Commons, Family, Life Course, and Society Commons, International Public Health Commons, Maternal and Child Health Commons, Obstetrics and Gynecology Commons, and the Women's Health Commons How does access to this work benefit you? Let us know!

\section{Recommended Citation}

Tapsoba, Placide, Dalomi Bahan, Emily Forsyth Queen, Gisele Kaboré, and Sally Hughes. 2013. "Quality of care and client willingness to pay for family planning services at Marie Stopes International in Burkina Faso." Ouagadougou: Population Council. 
Quality of care and client willingness to pay for family planning services at Marie Stopes International in Burkina Faso

Authors: Placide Tapsoba, Dalomi Bahan, Emily Forsyth Queen, Gisèle Kaboré, Sally Hughes

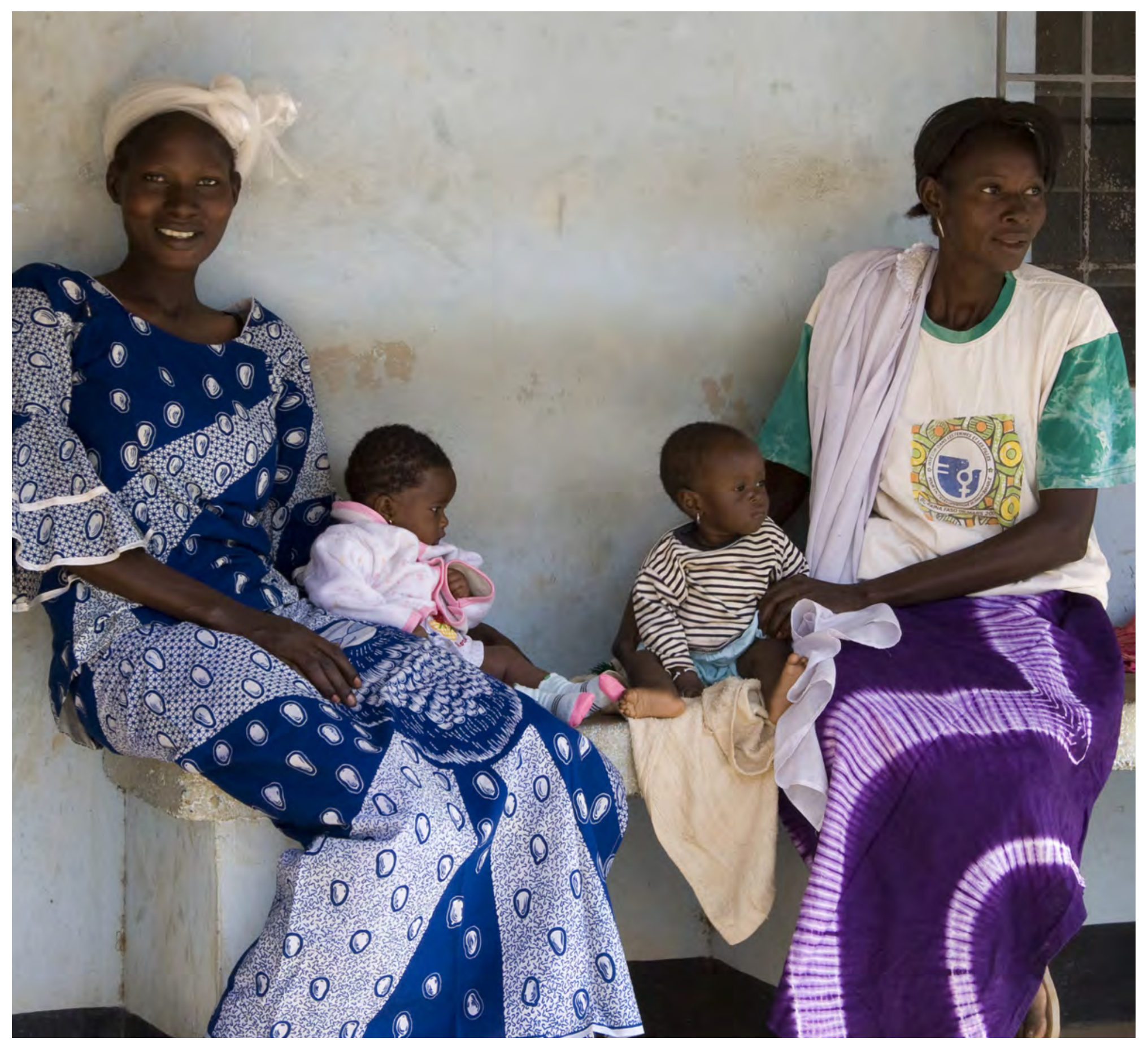




\section{Acronyms \\ EPI Info A public domain statistical software for \\ NGO Non governmental organisation epidemiology \\ SPSS Statistical Package for the Social \\ Sciences \\ FCFA Franc de la Communauté Financière \\ SRH Sexual and reproductive health \\ FP Family planning \\ IUD Intrauterine device \\ USAID United States Agency for International \\ Development \\ LAPM Long-acting and permanent method WTP Willingness to pay \\ MSI Marie Stopes International}

\section{Acknowledgements}

The Population Council would like to thank all the organisations and individuals who contributed to the success of this study. We wish to first thank Marie Stopes International (MSI) for their support during the study. Secondly, we would like to thank public sector and MSI service providers and MSI facility staff for their collaboration during the data collection exercise. Finally, the Council also wishes to thank the clients who cooperated and provided information to make the study possible.

\section{www.popcouncil.org}

This study is made possible by the generous support from the American people through the United States Agency for International Development (USAID) under the terms of Cooperative Agreement AIDOAA-A-10-00059. The contents are the responsibility of the Population Council and do not necessarily reflect the views of USAID or the United States Government.

Placide Tapsoba ${ }^{1}$, Dalomi Bahan², Emily Forsyth Queen ${ }^{3}$, Gisèle Kaboré ${ }^{4}$ and Sally Hughes ${ }^{3}$

${ }^{1}$ Population Council, 14B Ridge Rd, Roman Ridge, PMT CT 4906 Cantonments, Accra, Ghana

${ }^{2}$ Consultant, Ouagadougou, Burkina Faso.

${ }^{3}$ Marie Stopes International, Blvd Tengsoba, Patte d'Oie, Ouagadougou, Burkina Faso

${ }^{4}$ Population Council, 36 Avenue de la Liberté, Ouagadougou, Burkina Faso

\section{Suggested citation}

Tapsoba P., Bahan D., Forsyth Queen E., Kaboré G., Hughes S. Quality of care and client willingness to pay for family planning services at Marie Stopes International in Burkina Faso. Ouagadougou: Population Council, 2013.

\section{(C) 2013 The Population Council, Inc}

\section{Cover photograph credit}

Marie Stopes International / Ina Sotirova 


\section{Contents}

Executive summary

1. Context and justification 01

2. Methodology 02

$\begin{array}{ll}2.1 \text { Study sites } & 02\end{array}$

$2.2 \mathrm{MSI}$ and public sector prices 02

2.3 Prices tested in the study
02

$\begin{array}{ll}2.4 \text { Target population } & 04\end{array}$

2.5 Fieldwork, analysis and limitations 04

3. Respondent characteristics, knowledge, use and perceived quality of MSI services 05

3.1 Characteristics of respondents

$\begin{array}{ll}3.2 \text { Knowledge of MSI clinics } & 07\end{array}$

$\begin{array}{ll}3.3 \text { Use of MSI services } & 08\end{array}$

$\begin{array}{ll}3.4 \text { Quality of MSI services } & 11\end{array}$

4. Willingness to pay for MSI's family planning services 12

4.1 Payment for services $\quad 12$

4.2 Willingness to pay: estimation of demand and estimated revenue 12

5. Conclusions and recommendations 19

References / Bibliography 22

List of tables

Table 1: Summary table of current prices and proposed price increases iv

Table 2: MSI and public sector prices, in FCFA 07

Table 3: Prices tested by type of facility, in FCFA 07

Table 4: Distribution of the sample by contraceptive method and type of facility 07

Table 5: Socio-demographic characteristics of respondents, by facility type 09

Table 6: Occupation of respondents and partners, by facility type 10

Table 7: Reasons for choosing MSI, by facility type 12

Table 8: Current use utilization of MSI FP services, by facility type 13

Table 9: Methods previously used to avoid or delay pregnancy and place of procurement, by facility type 14

Table 10: Willingness to pay by level of increment and facility type 16

List of figures

Figure 1: Map of survey sites 02

Figure 2: Sources of information about MSI facility, by facility type (\%) 07

Figure 3: Alternative client solutions if prices are increased

(for clients who were resistant to any price increase) (\%) 12

Figure 4: Willingness to pay for implants at the Patte d'Oie centre 15

Figure 5: Estimated revenue from implants at the Patte d'Oie centre 15

Figure 6: Willingness to pay for implants at outreach sites 14

Figure 7: Estimated revenue for implants at outreach sites 14

Figure 8: Willingness to pay for IUD at the Patte d'Oie centre 15

Figure 9: Estimation of expected revenue from IUD at the Patte d'Oie centre 15

Figure 10: Willingness to pay for IUD at outreach sites 16

Figure 11: Estimated revenue from IUD at outreach sites 16 


\section{Executive summary}

Many sexual and reproductive health programmes operating in resource limited setting face a challenging balancing act. How can they make services accessible and affordable to clients, including those most in need, yet still be financially sustainable? A 'willingness to pay' survey is a tool that can help programmes to make informed decisions in this regard.

Willingness to pay (WTP) surveys measure the demand for products or services at a given price point by asking consumers, 'Would you purchase this product if it were offered at this price?' Results of these studies allow managers to estimate sales of products or services and project revenue from these sales. With this information, managers may set prices at a level that will generate income while retaining key consumer groups. A review of four WTP surveys in Ecuador, Guatemala, Mali and Pakistan demonstrate their reliability as valuable tools to predict client responses to prices changes.

Marie Stopes International's programme in Burkina Faso (MSI BF) initiated a WTP survey in 2011 and 2012. The study's principle objectives were to improve MSI BF's services and provide evidence to inform strategies aimed at improving financial sustainability. Increasing the prices of products and services would allow MSI BF to generate financial resources to sustain activities and to more deeply subsidise services to the most marginalised groups. However, raising prices could reduce demand for services, especially among the poor. To achieve the dual objectives of providing services to the poor and achieving sustainability, this WTP study examined the current situation and numerous pricing options, proposing optimal prices for MSI BF's products and services.

In Burkina Faso, women and men are accustomed to paying for family planning products and services through the public sector. User fees of between US $\$ 0.20$ and US \$1 are charged for pills and injectables. However, lack of access to long-acting and permanent FP methods through the public sector means that little is known about client willingness to pay for these methods.

This report describes how the WTP methodology was used by MSI BF and the key findings that resulted. The study examined 45 sites within the following regions:
Centre, Plateau Central and Centre-Sud. We used two sets of questionnaires: one for MSI's Patte d'Oie permanent centre in Ouagadougou and the second for its mobile clinical outreach service delivery sites.

Three family planning (FP) methods were selected for the questionnaires - tubal ligation, implants and the intrauterine device (IUD) in order to examine willingness to pay combined with three alternative price levels. However, the number of clients choosing tubal ligation as an FP method was not high enough in number to be statistically significant and was therefore not analysed.

Short-term methods were excluded from this study. Condoms, pills and injectabes are availability through all public sector sites at which MSI conducts mobile outreach; therefore MSI does not routinely provide these methods on outreach. Although MSI does offer short-term methods in the Patte d'Oje centre, public sector prices and the established private market for short-term methods, e.g. private pharmacies, largely guide prices.

All clients who answered the willingness to pay questions also completed a subsection on client satisfaction. Additionally, clients from the Patte d'Oie centre who used pills and injectables were exclusively asked questions from the client satisfaction subsection. Data collection was accomplished through exit interviews.

In the study, 1,772 clients were interviewed: 1,466 (83\%) at outreach sites and 306 clients (17\%) at the centre. Implant users accounted for $46 \%$ and IUD users accounted for $35 \%$ of interviewees. Respondents' ages varied: $30 \%$ of clients were between 15 and 24 years of age; $41 \%$ were between 25 and 34 years; and $29 \%$ of clients were 35 years or older. Most respondents (93\%) were married or living with a partner and reported their principal information sources across channels being an MSI client, a community based distributor or a health worker from a government post. Furthermore, 82\% of all respondents had no formal education, or were unable to complete primary education. Forty-six percent of respondents were farmers or pastoralists, $22 \%$ were housewives or unemployed, while traders accounted for $15 \%$, and unskilled workers for $11 \%$. 
It is important to note that one of the main differences between the centre and outreach clients was income level, with higher levels of poverty among outreach clients. Overall, about a third (37\%) of respondents reported living on less than $\$ 1.25$ per day. Four out of 10 mobile clinic respondents, compared to one in 10 at the Patte d'Oie centre, reported living on less than $\$ 1.25$ per day. More than half (51\%) of respondents reported learning about MSI through another client, and the three primary reasons for choosing an MSI centre or a mobile outreach for services were low cost (59\%), reputation (23\%) and proximity (15\%).

Clients were asked about their satisfaction with various aspects of MSI's services, including hours of operation, cleanliness, waiting times, service costs, service quality, client reception, staff discretion, consultation duration and acceptability of services or care. For all aspects investigated, more than $90 \%$ of respondents were either satisfied or very satisfied. The average time it took for clients to reach a service location was estimated at 46 minutes (39 minutes to the Patte d'Oie centre and 49 minutes to mobile clinics). Eighty-three percent of respondents indicated that MSI's services met their expectations, with $16 \%$ reporting MSI exceeded their expectations.

When questioned about willingness to pay, five percent of respondents did not agree to any price increase while four percent were willing to support only the lowest price increment category. Ten percent of respondents agreed to the medium increment, but the majority (80\%) agreed to the highest. Of the respondents not agreeing to any increase, 44\% indicated that they would switch to another method if the price of their current method was increased.

Analysis of respondent interview data indicates that prices at outreach sites could be set at \$3 (1,500 FCFA) for implants and \$2 (1,000 FCFA) for IUD; while at the Patte d'Oie centre prices could be set at $\$ 5$ (2,500 FCFA) for implants and \$4 (2,000 FCFA) for IUDs (for tubal ligation the number of clients interviewed was not sufficient to constitute a representative sample). By aiming to set service prices at these rates, income from clients can contribute to the programme aim of sustainability and allow greater discretion to provide deep subsidies to the most marginalised clients.

The process of implementing the WTP survey was insightful for MSI BF as it provided evidence on client satisfaction with services and willingness to contribute the cost of their implant or IUD. In light of the findings, MSI BF decided to increase prices for implants and IUDs both in centres and on outreach. However, balancing the benefit from slightly increased revenue with the risk that some poor clients might be dissuaded from seeking FP by higher prices, MSI BF decided to implement only an incremental price increase.

TABLE 1: Summary table of current prices and proposed price increases

\begin{tabular}{|c|c|c|c|c|}
\hline Method & $\begin{array}{l}\text { Current price } \\
\text { USD }^{1}(\text { FCFA) }\end{array}$ & $\begin{array}{l}\text { Proposed price } \\
\text { USD (FCFA) }\end{array}$ & $\begin{array}{l}\% \text { of clients } \\
\text { willing to pay }\end{array}$ & $\begin{array}{l}\text { Estimated revenue } \\
\text { USD } \\
\text { (FCFA) }\end{array}$ \\
\hline \multicolumn{5}{|c|}{ Patte d'Oie centre } \\
\hline IUD & $\$ 1$ (FCFA 500) & $\$ 4$ (FCFA 2,000) & $68 \%$ & $\$ 1,420(700,000)$ \\
\hline Implant & $\$ 4$ (FCFA 2,000) & $\$ 5$ (FCFA 2,500) & $90 \%$ & $\$ 4,460$ (2.2 million) \\
\hline \multicolumn{5}{|c|}{ Outreach sites } \\
\hline IUD & $\$ 1$ (FCFA 500) & $\$ 2$ (FCFA 1,000) & $85 \%$ & $\$ 12,170$ (6 million) \\
\hline Implant & $\$ 1.20$ (FCFA 600) & \$3 (FCFA 1,500) & $64 \%$ & $\$ 15,820$ (7.8 million) \\
\hline
\end{tabular}




\section{Context and justification}

Marie Stopes International (MSI) is a non governmental organisation (NGO) providing family planning (FP) and sexual and reproductive health $(\mathrm{SRH})$ services in more than 40 countries, including Burkina Faso. MSI began its activities in Burkina Faso in 2009, creating awareness and providing the full range of FP services including methods such as implants, IUDs and tubal ligations. It is MSI's goal to provide FP services at an affordable or subsidised price.

Like most FP programmes run by NGOs, MSI is challenged with maintaining its social mission of providing FP services to the poorest at reduced prices while simultaneously maximising cost recovery to improve programme sustainability. One option for ensuring sustainability is allowing MSI to generate financial resources by increasing service prices; but this strategy could reduce service demand, especially among poor populations. Therefore, to fulfil its mission while ensuring sustainability, MSI must identify optimal prices for its services. This need informed the study. Currently the most common MSI programme strategy internationally is to recover costs in urban centres and to offer services free or at very low cost via mobile clinical outreach services. However, this may vary from programme to programme and willingness to pay studies can support in-country decision making.
The main objectives of the study are:

- determining clients' demographic and socio-economic characteristics

- $\quad$ estimating client satisfaction

- $\quad$ determining the willingness to pay for FP services

- calculating demand and revenue curves for tubal ligations, IUDs and contraceptive implants offered by centres and outreach services

- $\quad$ estimating optimal prices for selected contraceptive methods.

The study report comprises five parts: the first details the context and justification for the study and the second deals with methodological aspects. The three remaining sections discuss the study's results, which characterise the survey respondents' demographic profiles and MSI's visibility; the quality of MSI's services and its client satisfaction; and an estimation of demand and revenue for the two methods that were accessed in significant numbers: IUD and implants. The conclusion section summarises findings and also provides guidance for other programmes that wish to conduct similar surveys.

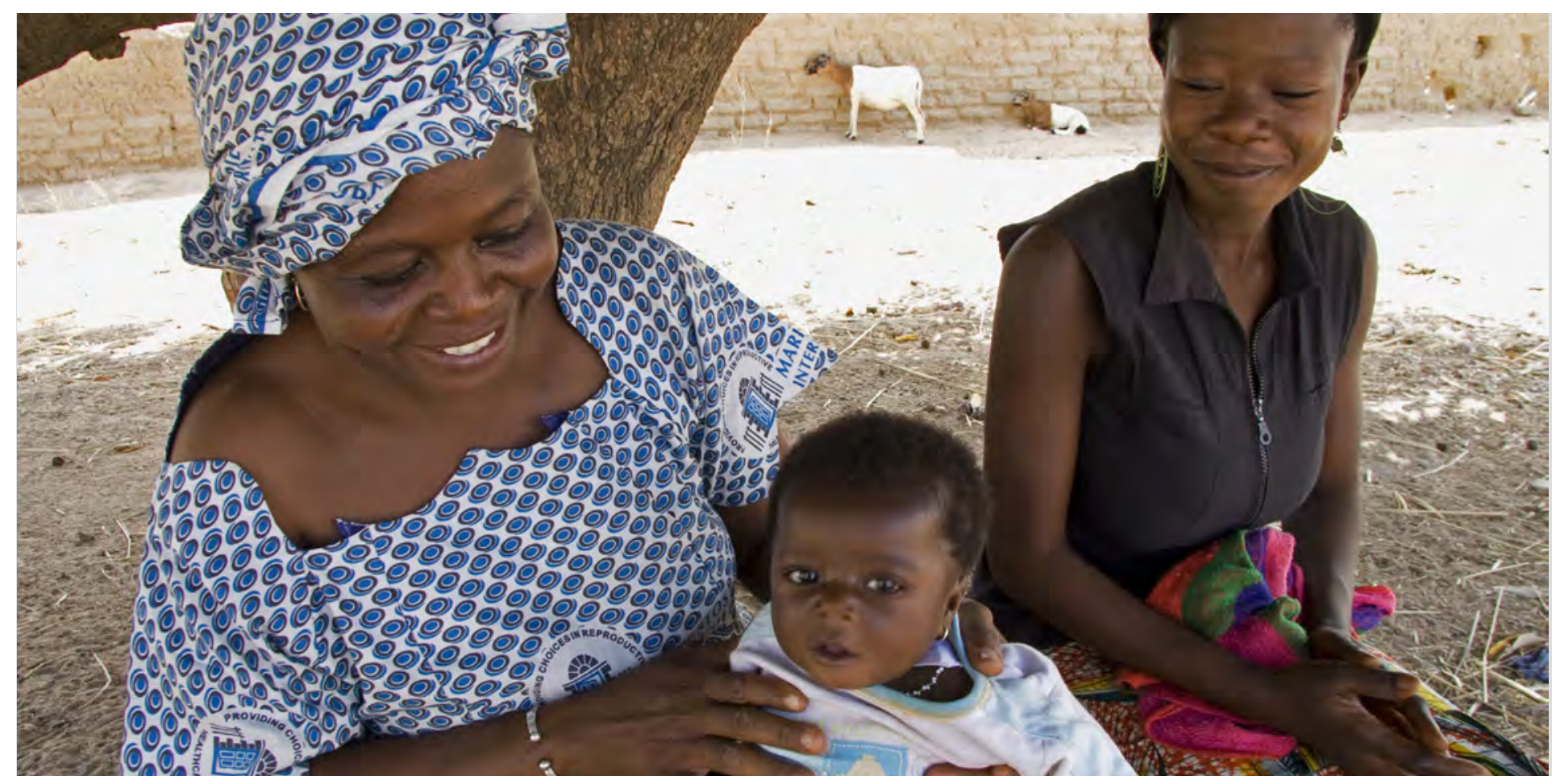




\section{Methodology}

\subsection{Study sites}

This study explored 45 sites in the Centre, Plateau

Central and Centre-Sud regions of Burkina Faso.

Survey sites are indicated in Figure 1. These included

the health districts of Bogodogo, Boulmiougou,

Nongre-Masson, Sig-Noghin, Boussé, Kombissiri,

Saponé and Ziniaré.

FIGURE 1: Map of survey sites

\section{Survey sites accepting family planning payment services offered by Marie Stopes International}
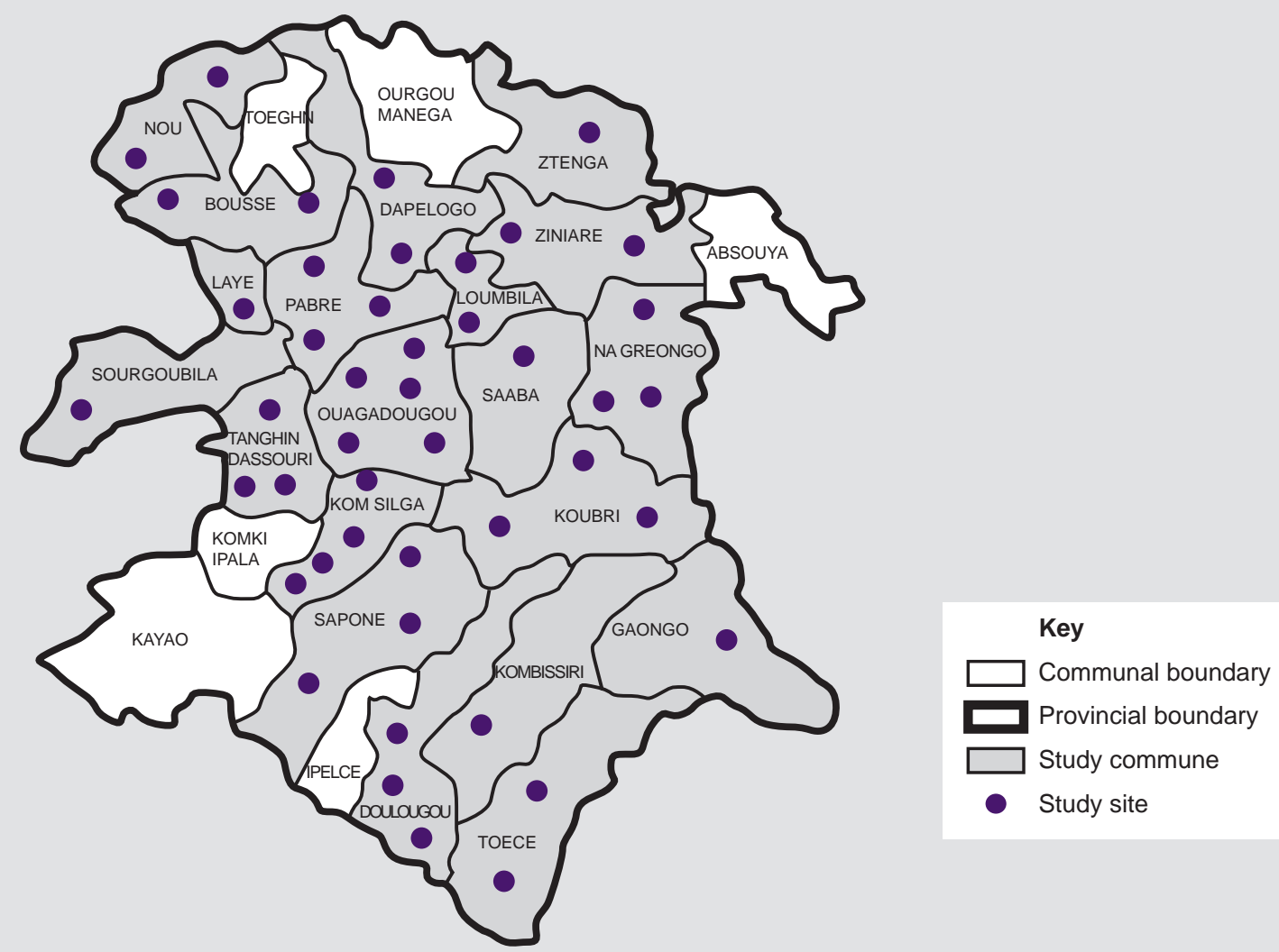

\subsection{MSI and public sector prices}

Table 2 compares the prices of MSI Burkina Faso and public sector prices for FP products and services at the time of the study. With the exception of threemonth injectables and the implant in the Patte D'Oie centre located in Ouagadougou, MSI prices were lower than the public sector prices, reflecting MSI's commitment to reaching the poor.

\subsection{Prices tested in the study}

To estimate optimal prices for achieving sustainability and affordable services, the study tested three price increments for each of the two identified methods: IUD and implants. These prices are illustrated in accordance with facility type in Table 3. 
TABLE 2: MSI and public sector prices, in USD (FCFA)

\begin{tabular}{|c|c|c|c|}
\hline Method & $\begin{array}{l}\text { Patte d'Oie centre } \\
\text { price }\end{array}$ & $\begin{array}{l}\text { MSI outreach } \\
\text { price }\end{array}$ & Public sector ${ }^{3}$ \\
\hline Tubal ligation & $\$ 4$ (FCFA 2,000) & $\$ 1$ (FCFA 500) & $\$ 17.75$ (FCFA 8,750) \\
\hline Vasectomy & $\$ 1$ (FCFA 500) & $\$ 1$ (FCFA 500) & n/a \\
\hline IUD & \$1 (FCFA 500) & $\$ 1$ (FCFA 500) & $\$ 1.6$ (FCFA800) \\
\hline Implant & $\$ 4$ (FCFA 2,000) & $\$ 1.2$ (FCFA600) & $\$ 2$ (FCFA 1,000) \\
\hline 3 month injectable & $\$ 1.4$ (FCFA 700) & $\mathrm{n} / \mathrm{a}$ & $\$ 1$ (FCFA 500) \\
\hline Pill (cycle) & $\$ 0.2$ (FCFA 100) & $\mathrm{n} / \mathrm{a}$ & $\$ 0.2$ (FCFA 100) \\
\hline
\end{tabular}

TABLE 3: Prices tested by type of facility, in USD (FCFA)

\begin{tabular}{|c|c|c|c|c|}
\hline Method & $\begin{array}{l}\text { Current } \\
\text { price }\end{array}$ & $\begin{array}{l}\text { Low } \\
\text { increment }\end{array}$ & $\begin{array}{l}\text { Medium } \\
\text { increment }\end{array}$ & High increment \\
\hline \multicolumn{5}{|c|}{ Patte d'Oie centre } \\
\hline IUD & $\$ 1$ (FCFA 500) & $\$ 1.6$ (FCFA 800) & $\$ 3$ (FCFA 1,500) & $\$ 4$ (FCFA 2,000) \\
\hline Implant & $\$ 4$ (FCFA 2,000) & $\$ 5$ (FCFA 2,500) & $\$ 6$ (FCFA 3,000) & $\$ 10$ (FCFA 5,000) \\
\hline \multicolumn{5}{|c|}{ Outreach sites } \\
\hline IUD & $\$ 1$ (FCFA 500) & $\$ 1.6$ (FCFA 800) & $\$ 2$ (FCFA 1,000$)$ & $\$ 2.5$ (FCFA 1,250) \\
\hline Implant & $\$ 1.2$ (FCFA 600) & $\$ 1.6$ (FCFA 800) & $\$ 2$ (FCFA 1,000) & $\$ 2.5$ (FCFA 1,500) \\
\hline
\end{tabular}

TABLE 4: Distribution of the sample by contraceptive method and type of facility

\begin{tabular}{|lllll|} 
& Tubal ligation & IUD & Implant & Pillinjectable \\
\hline Patte d'Oie centre & 3 & 53 & 114 & 85 \\
\hline Mobile outreach & 68 & 698 & 700 & $\mathrm{n} / \mathrm{a}$ \\
\hline Total & $\mathbf{7 1}$ & $\mathbf{7 5 1}$ & $\mathbf{8 1 4}$ & $\mathbf{8 5}$ \\
\hline
\end{tabular}




\subsection{Target population}

This study was conducted at the Patte d'Oie centre situated in Ougadougou and at sites served by MSI mobile outreach teams to rural health centres. The study's target population was women seeking MSI FP services. Three FP methods were selected for analysis at mobile outreach clinic sites - IUD, female sterilisation and implants. Four methods were selected at the Patte d'Oie centre - IUD, implants, pills and injectables. Respondents were all consenting clients obtaining one of these contraceptive services during a five-week period.

During the five-week study, interviewers surveyed all consenting clients at Patte d'Oie, from the time the centre opened to the time the centre closed on all days the centre was open. Each outreach site was visited one time for one full business day and all consenting clients were interviewed. The large difference in sampled clients between the Patte d'Oie centre and outreach sites is due to the higher number of family planning clients at outreach sites than at the Patte d'Oie centre, where a wider range of services is offered. There were three teams conducting research simultaneously at three outreach sites and just one team at the Patte d'Oie centre.

Table 4 shows the distribution of the sample by method and facility type (Patte d'Oie centre or mobile outreach).

There were insufficient tubal ligation clients at the Patte d'Oie centre for a representative sample to analyse willingness to pay.

\subsection{Fieldwork, analysis and limitations}

Seven interviewers were recruited and trained for two days (from 29th to 30th November 2011) on concepts, role playing and instrument pre-testing. Interviews were conducted from 5th December 2011 to 18th January 2012. The MSI Burkina Faso provider informed women about the study after their consultation, and clients were then interviewed after receiving their service. Interviewers obtained women's consent after explaining the study's objectives.
Willingness to pay (WTP) surveys measure the potential demand for products or services by asking consumers "Would you purchase this product if it were offered at this price?" WTP survey data permit programme managers to estimate the number of clients who will pay a given price and the amount of revenue that will be generated by that price. This then allows programmes to set or increase prices charged for services with an evidence based idea of how this will affect demand.

A review of four WTP surveys for reproductive health programmes in developing countries (Pakistan, Mali, Guatemala and Ecuador) found that these surveys are reliable and valid and, as a result, help programme managers to predict client responses to price changes more accurately ${ }^{4}$. There is a useful Population Council manual that provides more detail on how to conduct such a survey, including sample instruments and application of WTP in three countries ${ }^{5}$.

Some of the benefits of WTP surveys identified in this manual are:

- the survey methodology is simple

- the survey has been used successfully with populations without formal education and provided internally consistent responses

- $\quad$ estimates are conservative, typically underestimating maximum WTP and therefore protecting programme managers from raising prices too much.

EPI Info software was used for data entry and Statistical Package for the Social Sciences (SPSS) for data analysis. Fieldwork involved a few challenges, including convincing clients to wait for the interview after receiving their service. One limitation of the study is that there was the possibility that some women found MSI's existing prices prohibitive and therefore did not come to the centres for family planning, therefore excluding them from the study by default. Secondly, the survey was written in French but conducted in local languages (primarily Moore). Although interviewers were trained on translation, the survey was not translated in written form and therefore complete consistency in translation cannot be guaranteed. 


\section{Respondent characteristics, knowledge, use and perceived quality of MSI services}

During the survey, 1,772 people were interviewed: $1,466(83 \%)$ at outreach sites and $306(17 \%)$ at the Patte d'Oie centre. The difference was due to the greater number of clients served by the three outreach teams compared to the one centre team.

\subsection{Characteristics of respondents}

\subsubsection{Socio-demographic characteristics of respondents}

Table 5 represents respondents'

socio-demographic backgrounds. Almost all clients were women, with the exception of one male client who was interviewed at the Patte d'Oie centre but was excluded from analysis. No male clients were interviewed at the outreach sites.

TABLE 5: Socio-demographic characteristics of respondents, by facility type

\begin{tabular}{|c|c|c|c|}
\hline & Patte d'Oie (\%) & Outreach (\%) & Total $(\%)$ \\
\hline \multicolumn{4}{|l|}{ Age groups (\%) } \\
\hline $15-24$ & 36 & 29 & 30 \\
\hline $25-34$ & 48 & 40 & 41 \\
\hline 35 or more & 16 & 31 & 29 \\
\hline Median age & 27 & 29 & 28 \\
\hline Mean age & 28 & 29 & 30 \\
\hline \multicolumn{4}{|l|}{ Marital status (\%) } \\
\hline Single/widowed/separated/divorced & 18 & 5 & 7 \\
\hline Married or living with partner & 82 & 95 & 93 \\
\hline \multicolumn{4}{|c|}{ Number of children living in household (\%) } \\
\hline 0 & 11 & 2 & 3 \\
\hline 1 & 31 & 12 & 15 \\
\hline 2 & 23 & 18 & 19 \\
\hline 3 & 19 & 18 & 18 \\
\hline 4 & 9 & 16 & 15 \\
\hline 5 & 4 & 14 & 12 \\
\hline 6 or more & 2 & 21 & 17 \\
\hline Mean number of children & 2 & 4 & 3 \\
\hline Respondents (n) & 306 & 1,466 & 1,772 \\
\hline
\end{tabular}


The median and mean ages reflect the fact that respondents were mostly young women, and those interviewed at Patte d'Oie were younger than those interviewed at outreach sites. A third (30\%) of respondents were under 25 years of age, while $41 \%$ were between 25 and 34 years, with the remainder being 35 and older (29\%).

More than $93 \%$ of women were either married or living with a partner. At the outreach sites, more respondents were married compared to the urban Patte d'Oie centre. The number of children living in respondent households varied between zero and ten, with the average number being three. Half of respondents had no more than three children. The average and the median number of children was higher among respondents at outreach sites where one in five clients had six or more children (see Table 5). Average household sizes and number of children were higher in rural areas than at the urban centre.

\subsubsection{Occupation of respondents and partners}

Overall, $46 \%$ of respondents were farmers or pastoralists. The next most popular occupation given was housewife or unemployed, followed by trader or manual unskilled labourer (see Table 5). Differences in respondents' and partners' occupations were pronounced at Patte d'Oie and outreach sites.

Based on exit interviews ${ }^{6}, 42 \%$ of MSI outreach clients live on less than $\$ 1.25$ per day (purchasing power parity: 312 FCFA in 2010) and 75\% live on less than $\$ 2.50$ per day (purchasing power parity: 624 FCFA in 2010). At the Patte d'Oie centre, $12 \%$ of the clients live on less than $\$ 1.25$ per day and $39 \%$ live on less than $\$ 2.50$ per day.

TABLE 6: Occupation of respondents and partners, by facility type

\begin{tabular}{|c|c|c|c|}
\hline & Patte d'Oie (\%) & Outreach (\%) & Total (\%) \\
\hline \multicolumn{4}{|l|}{ Occupation of respondent (\%) } \\
\hline Agriculture/pastoralist & 2 & 55 & 46 \\
\hline Unemployed/housewife & 31 & 20 & 22 \\
\hline Sales and services & 25 & 13 & 15 \\
\hline Unskilled manual & 18 & 9 & 11 \\
\hline Student & 13 & 3 & 4 \\
\hline Skilled manual & 3 & 0 & 1 \\
\hline Clerical & 6 & 0 & 1 \\
\hline Professional/technical/managerial & 1 & 0 & 0 \\
\hline \multicolumn{4}{|l|}{ Occupation of partner (\%) } \\
\hline Agriculture/pastoralist & 7 & 65 & 55 \\
\hline Unskilled manual & 23 & 14 & 16 \\
\hline Sales and services & 30 & 10 & 13 \\
\hline Skilled manual & 10 & 2 & 4 \\
\hline Clerical & 17 & 2 & 4 \\
\hline Unemployed/housewife & 1 & 3 & 3 \\
\hline Professional/technical/managerial & 4 & 0 & 1 \\
\hline Student & 1 & 1 & 1 \\
\hline Not declared & 7 & 3 & 4 \\
\hline Respondents (n) & 306 & 1,466 & 1,772 \\
\hline
\end{tabular}




\subsubsection{Information sources of respondents}

As indicated in Figure 2, the primary information source for clients within the preceding two weeks was radio, followed by television. Respondents from Patte d'Oie were more likely to watch television and listen to the radio compared to those at outreach sites. Only two percent overall read a newspaper, primarily those at Patte d'Oie, and virtually none read a magazine or used the internet. These results indicate that print and electronic media use is restricted mainly to urban areas.

\subsection{Knowledge of MSI clinics}

The three most commonly cited sources of knowledge about MSI's services were a former client (54\%), an MSI social marketing agent or peer educator (46\%), and a government facility (30\%) (see Figure 2). When asked to cite the one source of information that influenced them the most to visit the centre, respondents cited the same top three responses: a former client (39\%); MSI social marketing agents and peer educators (23\%); and referrals from government facilities (21\%). At outreach sites, community based marketing agents and government facility providers were the most influential sources, while at the Patte d'Oie centre, word of mouth from former clients primarily influenced the choice of MSI facility.

FIGURE 2: Sources of information about MSI facility, by facility type (\%)

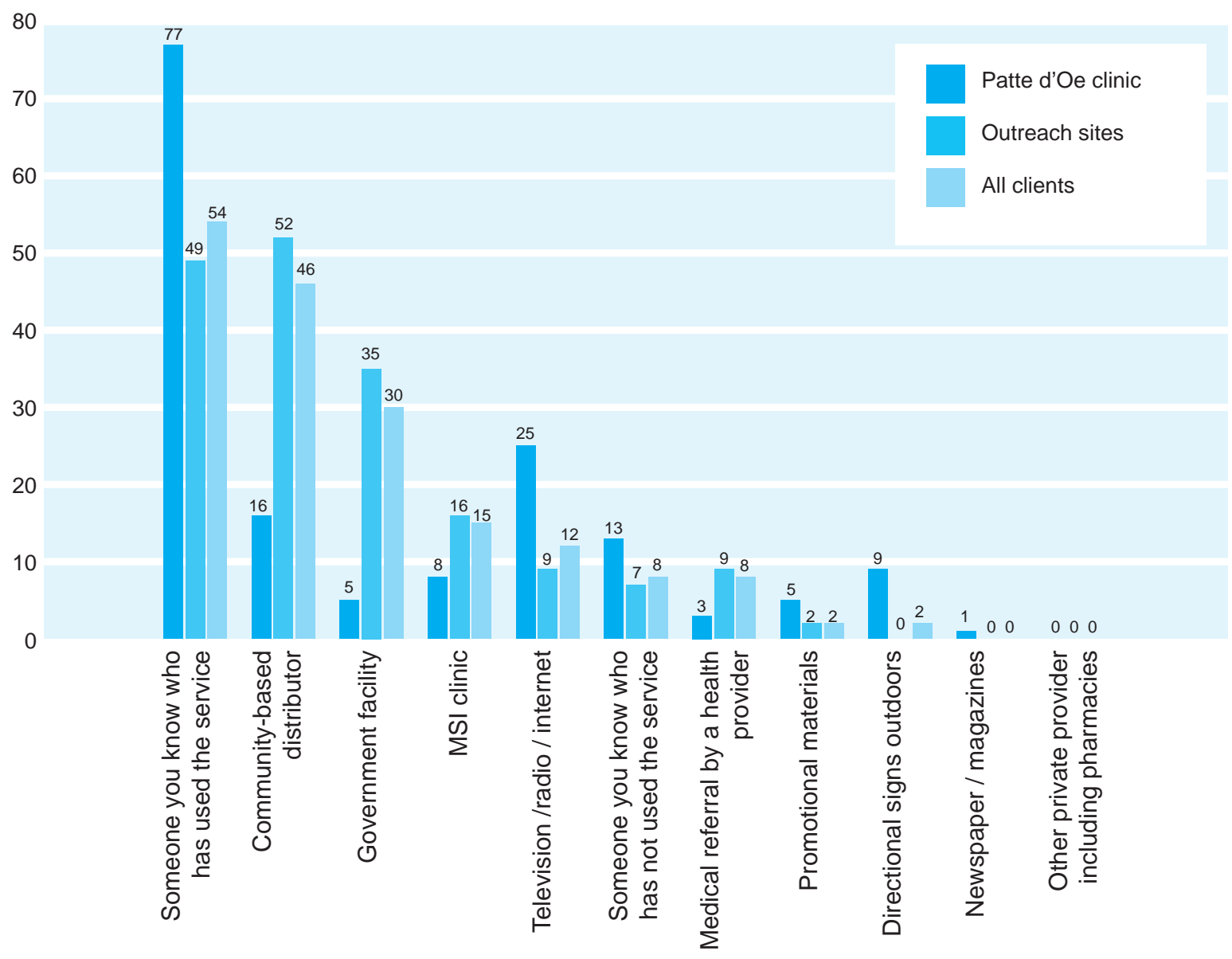


Respondents indicated choosing MSI centre services for three primary reasons: affordable cost; reputation of having good providers; and proximity (see Table 6). Reputation was the main reason cited by Patte d'Oie centre respondents, while affordability was the main reason cited by outreach team respondents.

TABLE 7: Reasons for choosing MSI, by facility type

\begin{tabular}{|c|c|c|c|}
\hline & $\begin{array}{l}\text { Patte d'Oie } \\
(\%)\end{array}$ & $\begin{array}{l}\text { Outreach } \\
(\%)\end{array}$ & $\begin{array}{l}\text { Total } \\
(\%)\end{array}$ \\
\hline Low cost & 36 & 63 & 58 \\
\hline Good reputation of provider & 44 & 18 & 23 \\
\hline Proximity & 9 & 16 & 15 \\
\hline Referred to this provider by another provider & 4 & 1 & 2 \\
\hline Others & 1 & 0 & 1 \\
\hline Services or medicines are available & 1 & 0 & 0 \\
\hline Respondents (n) & 306 & 1,466 & 1,772 \\
\hline
\end{tabular}

\subsection{Use of MSI services}

Of the three FP methods identified for the study, implants were the most commonly used (46\%) followed by IUD (35\%). Only 71 respondents (4\%) had chosen a tubal ligation (see Table 7). (Note that MSI only provides long-acting and permanent methods (LAPM) on outreach to complement existing shortterm methods available in primary level public facilities.) 
TABLE 8: Current use of MSI FP services, by facility type

\begin{tabular}{|c|c|c|c|}
\hline & $\begin{array}{l}\text { Patte d'Oie } \\
(\%)\end{array}$ & $\begin{array}{l}\text { Outreach } \\
(\%)\end{array}$ & $\begin{array}{l}\text { Total } \\
(\%)\end{array}$ \\
\hline FP counselling & 72 & 82 & 81 \\
\hline Implant & 37 & 48 & 46 \\
\hline Intrauterine device (IUD) & 14 & 39 & 35 \\
\hline Injectable & 28 & $\mathrm{n} / \mathrm{a}$ & 28 \\
\hline $\begin{array}{l}\text { Other sexual reproductive health } \\
\text { (e.g. Follow-up IUD, implants, tubal ligation) }\end{array}$ & 24 & 16 & 18 \\
\hline Contraceptive pills & 16 & $\mathrm{n} / \mathrm{a}$ & 16 \\
\hline Tubal ligation & 1 & 5 & 4 \\
\hline Removal of implant & 1 & 1 & 1 \\
\hline Removal of IUD & 2 & 1 & 1 \\
\hline Other general health & 2 & 0 & 1 \\
\hline Vasectomy & 1 & 0 & 0 \\
\hline Respondents (n) & 306 & 1,466 & 1,772 \\
\hline
\end{tabular}

Respondents were asked if they (or their partner) had done anything within the last three months to avoid or delay a pregnancy. Six out of every ten respondents had done something to delay or avoid pregnancy, varying from $80 \%$ among Patte d'Oie centre respondents to $56 \%$ among outreach site respondents. During the last three months, methods used by respondents to avoid or delay pregnancy included: three month contraceptive injectables (28\%); male condoms (18\%); IUDs (15\%); pills (13\%); and implants (13\%) (see Table 8). Twelve percent of women used traditional methods such as withdrawal or abstinence to avoid or delay pregnancy during the last three months. Some differences were observed between respondents at the Patte d'Oie centre and outreach site respondents, especially for IUDs, implants, pills and traditional methods. It also emerged that about two-thirds of respondents (62\%) obtained methods from providers other than MSI, especially in rural outreach areas.

According to the MSI definition of 'adopter' (someone who was not using a modern method of FP in the last three months), 55\% of FP clients at outreach sites and $24 \%$ of clients at the Patte d'Oie centre were adopters. 
TABLE 9: Methods previously used to avoid or delay pregnancy and place of procurement, by facility type

\begin{tabular}{|c|c|c|c|}
\hline & $\begin{array}{l}\text { Patte d'Oie } \\
(\%)\end{array}$ & $\begin{array}{l}\text { Outreach } \\
\text { (\%) }\end{array}$ & $\begin{array}{l}\text { Total } \\
(\%)\end{array}$ \\
\hline \multicolumn{4}{|l|}{ Methods } \\
\hline Injectable contraception & 30 & 27 & 28 \\
\hline Male condoms & 14 & 20 & 18 \\
\hline IUD & 8 & 16 & 15 \\
\hline Implants & 23 & 10 & 13 \\
\hline Contraceptive pills & 19 & 11 & 13 \\
\hline $\begin{array}{l}\text { Traditional methods } \\
\text { (withdrawal, rhythm, abstinence) }\end{array}$ & 4 & 14 & 12 \\
\hline Breast feeding & 0 & 2 & 2 \\
\hline Tubal ligation & 0 & 0 & 0 \\
\hline Female condoms & 0 & $\mathrm{n} / \mathrm{a}$ & 0 \\
\hline \multicolumn{4}{|l|}{ Place obtained } \\
\hline Other provider & 36 & 70 & 62 \\
\hline MSI & 60 & 23 & 32 \\
\hline Don't know & 1 & 5 & 4 \\
\hline Other MSI centre or outreach site & 4 & 2 & 2 \\
\hline Respondents (n) & 245 & 821 & 1,066 \\
\hline
\end{tabular}




\subsection{Quality of MSI services}

Respondents were invited to comment on operational aspects of MSI's activities including hours of operation, waiting time and location. Nine out of 10 respondents reported being satisfied or very satisfied with MSI's hours of operation, with no difference between the urban and rural centres.

The average time taken by clients to reach an MSI facility was estimated at 46 minutes overall, 39 minutes for Patte d'Oie clients and 49 minutes for those visiting outreach sites. The median duration was 30 minutes for all sites. For all clients, 90\% were either satisfied or very satisfied with the waiting time after registering, with $92 \%$ satisfaction for outreach site respondents and $82 \%$ for Patte d'Oie centre respondents.

Almost all respondents indicated that costs of services at MSI centres were affordable. Virtually all (98\%) respondents were either satisfied or very satisfied with the quality of services from MSI centre providers, regardless of facility type. Ninety-four percent of respondents were satisfied with the cleanliness of facilities they attended, with little difference between urban and rural centres.

Ninety-eight percent of respondents were satisfied or very satisfied with their reception by centre staff and providers, which was similar for both the permanent and mobile sites. Nearly all respondents were satisfied with discretion shown during consultation (99\%). Moreover, nearly all respondents were satisfied with their consultation duration (98\%) and felt satisfied with the services and care at both the Patte d'Oie centre and outreach sites.

In addition to being asked to independently assess various aspects of MSI's services, respondents were also asked to provide an overall assessment of their experiences: $99 \%$ were satisfied or very satisfied with their overall experience at MSI facilities.
Respondents were asked if they would visit an MSI facility again, or recommend it to another person. Nearly all respondents (99\%) indicated they would return for services and would recommend the centre to a friend. Respondents were asked to indicate three service aspects they would like to see improved. A compilation of open-ended responses showed that the primary aspects mentioned were:

(i) Eight out of 10 respondents had nothing to indicate in terms of service aspects they wished to see improved. They reported full satisfaction with MSI's services and suggested that the organisation should strive to sustain existing service quality.

(ii) MSI should improve upon the waiting time for receiving services by beginning services earlier, by increasing the number of providers at existing sites, and by increasing the number of outreach sites.

(iii) MSI should consider integrating additional services such as maternity and child health services into the existing ones.

(iv) About three percent of respondents proposed that the general population, especially spouses, should be introduced to FP. This was particularly important, as some spouses opposed contraceptive use. 


\section{Willingness to pay for MSl's family planning services}

\subsection{Payment for services}

Respondents who had recently received an IUD or implant from MSI were asked if they would pay for services if prices were increased. Three price increments were tested: low, medium and high. Results analysis indicates that five percent of respondents were resistant to any increase; four percent could support only a low incremental increase, while $10 \%$ supported a medium increase. Some $80 \%$ of respondents agreed to the high increment (see Table 9).

Of those who did not support any price increase $(n=80$ at outreach sites, $n=5$ at Patte d'Oie centre), 44\% said they would switch to another method, $29 \%$ would stop using contraceptives, and the rest would use another provider, were unsure of what to do, would ask someone for a loan, or would save up until they had enough money (see Figure 3).

\subsection{Willingness to pay: estimation of demand and estimated revenue}

This section takes the willingness to pay responses from interviews and translates this data into information that a programme can use for planning. Specifically, we provide separate demand estimates for the three identified methods at varying prices for the two facility types, as well as estimated revenues based on MSI's projected services for 2012.

TABLE 10: Willingness to pay by level of increment and facility type

\begin{tabular}{|c|c|c|c|}
\hline & Patte d'Oie (\%) & Outreach (\%) & Total (\%) \\
\hline No increment & 3 & 5 & 5 \\
\hline Low increment & 4 & 4 & 4 \\
\hline Medium increment & 16 & 10 & 10 \\
\hline High increment & 77 & 81 & 80 \\
\hline Respondents (n) & $171^{7}$ & 1,466 & 1,637 \\
\hline
\end{tabular}

FIGURE 3: Alternative client solutions if prices are increased (for clients who were resistant to any price increase) (\%)

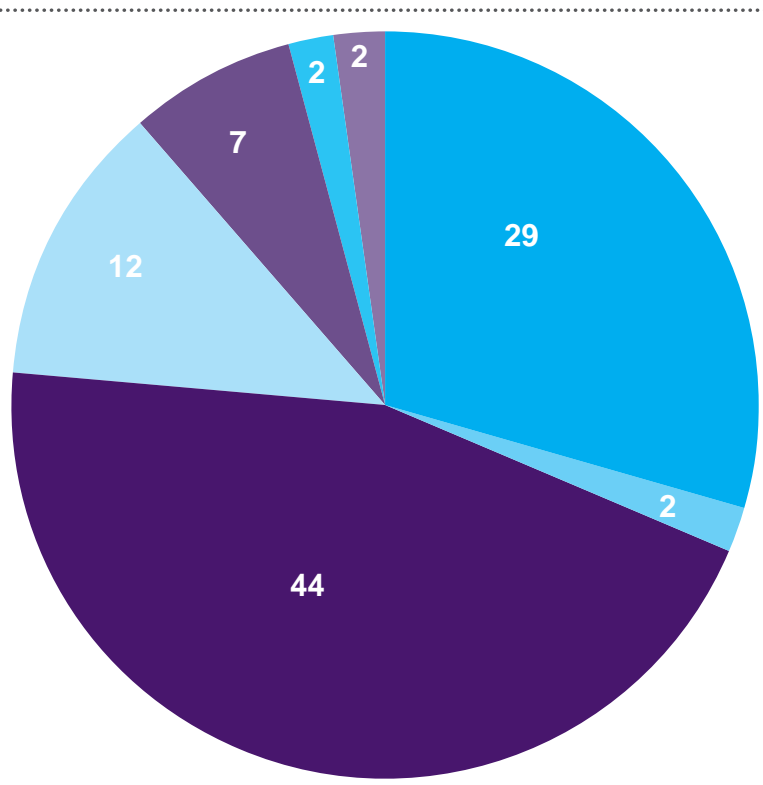

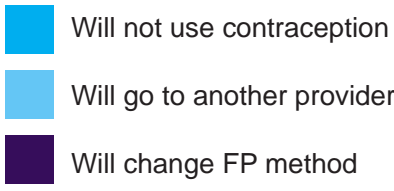

Will ask someone for financial support/loan Will save to pay requested price Don't know Other 


\subsubsection{Demand for implants and revenue expected from implants at the Patte d'Oie centre}

At the Patte d'Oie centre, 111 clients quoted the maximum price they were willing to pay, with results of quoted prices between $\$ 1.20$ (600 FCFA) and \$20.25 (10,000 FCFA) (see Figure 4). Nearly $90 \%$ of respondents could support prices up to $\$ 5(2,500$ FCFA), with nearly $50 \%$ supporting as much as $\$ 7$ $(3,500$ FCFA). Only five percent of respondents proposed prices exceeding $\$ 12$ (6,000 FCFA).

An implant insertion at the Patte d'Oie centre currently costs \$4 (2,000 FCFA), which generates an estimated revenue of $\$ 3,850$ (1.9 million FCFA) per year. To maximise revenue, the optimal price could be set at $\$ 5$ (2,500 FCFA), which would generate an estimated revenue of $\$ 4,460$ (2.2 million FCFA) per year. Ninety percent of clients would be willing to pay this revised price.

FIGURE 4: Willingness to pay for implants at the Patte d'Oie centre

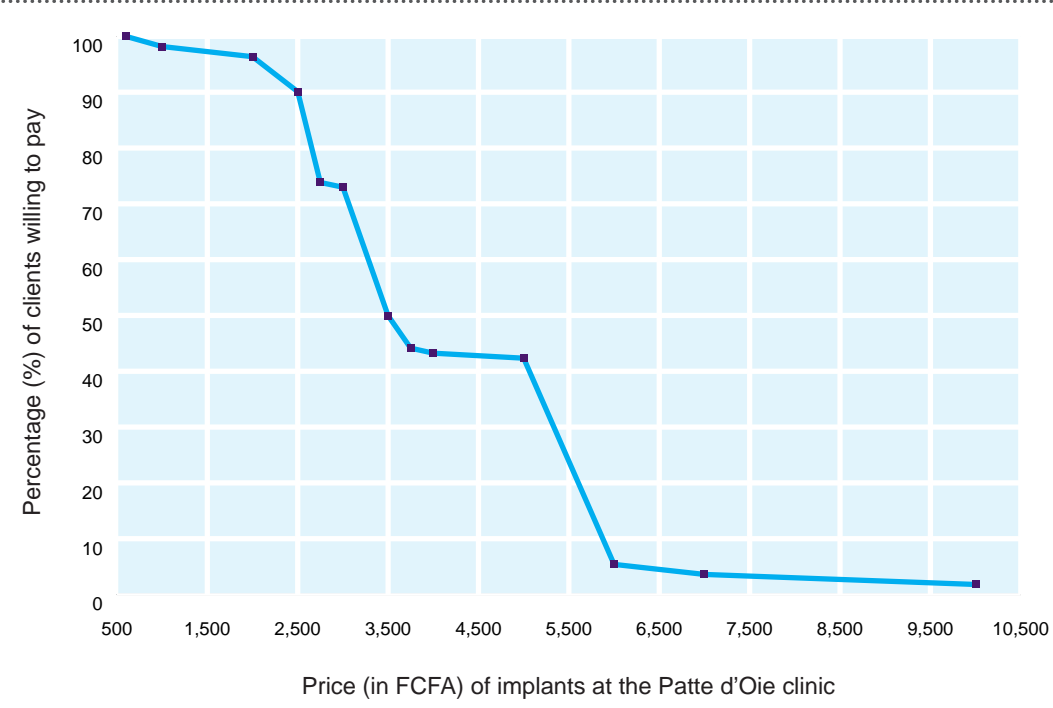

FIGURE 5: Estimated revenue from implants at the Patte d'Oie centre

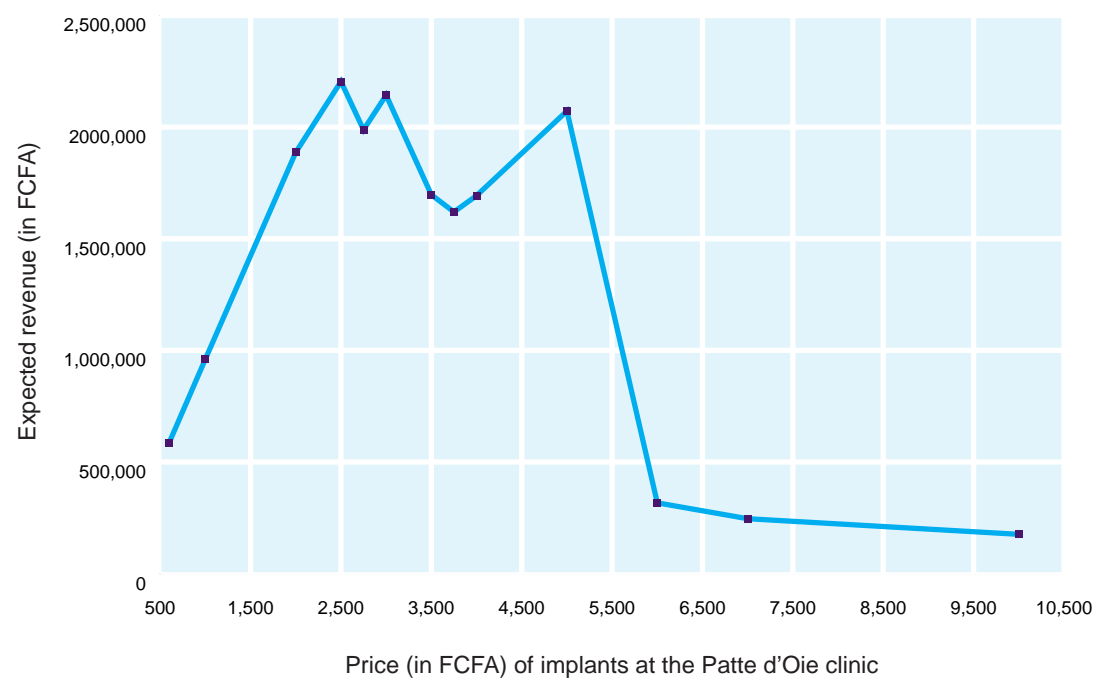




\subsubsection{Demand for implants and revenue expected from implants in outreach sites}

At outreach sites, 696 clients quoted the maximum price they were willing to pay, with results of quoted prices between \$1 (500 FCFA) and \$10 (5,000 FCFA) (see Figure 6). Nearly $85 \%$ of respondents could support prices up to $\$ 2$ (1,000 FCFA), with nearly $64 \%$ supporting as much as $\$ 3$ (1,500 FCFA). Only 10\% of respondents proposed prices exceeding $\$ 5.45$ (2,700 FCFA).
An implant insertion at outreach sites currently costs \$1.20 (600 FCFA), which generates an estimated revenue of $\$ 10,000$ (4.9 million FCFA). To maximise revenue, the optimal price should be set at $\$ 3(1,500$ FCFA), which would generate an estimated revenue of $\$ 15,820$ (7.8 million FCFA) per year. Sixty-four percent of clients would be willing to pay this revised price.

FIGURE 6: Willingness to pay for implants at outreach sites

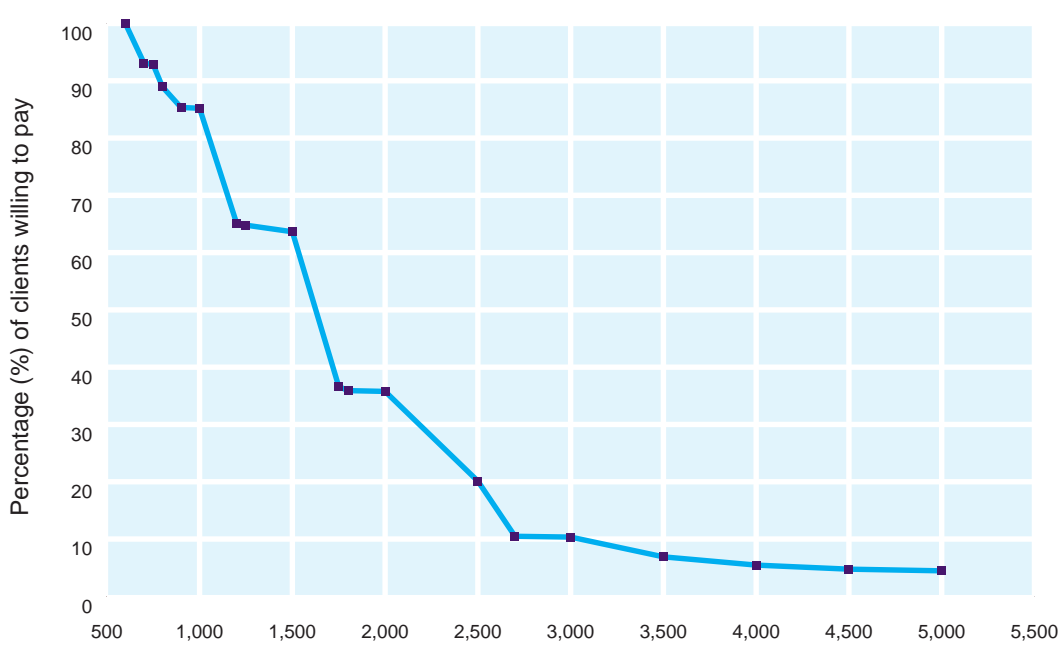

Price (in FCFA) of implants at outreach sites

FIGURE 7: Estimated revenue for implants at outreach sites

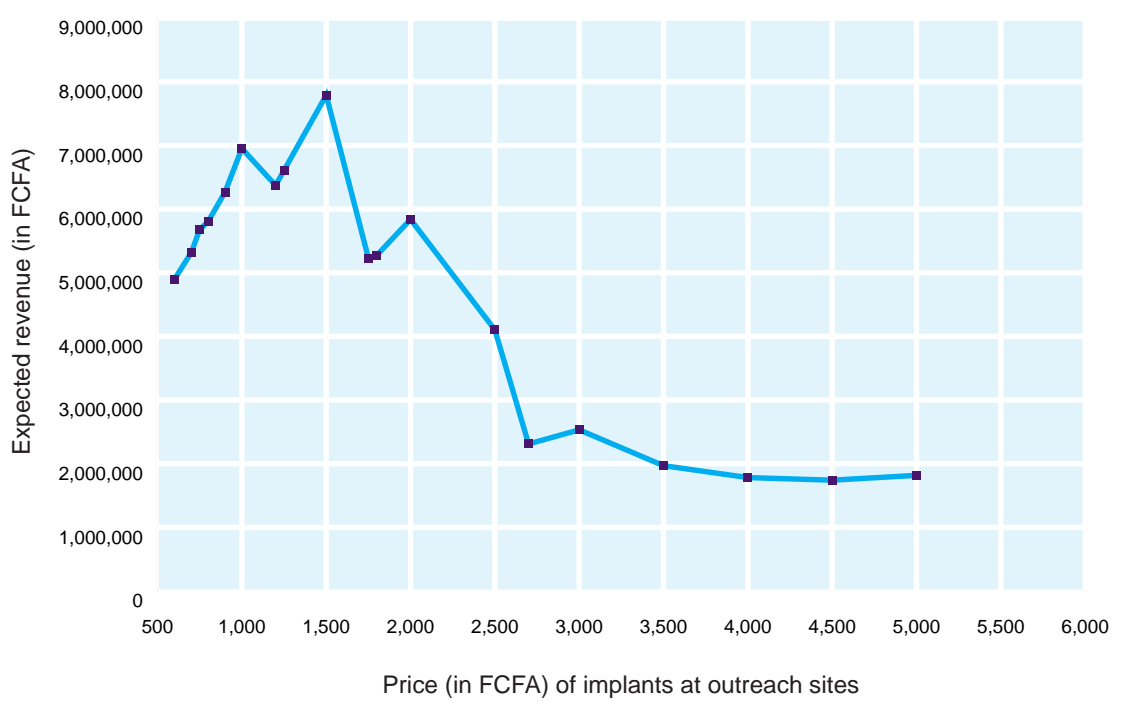




\subsubsection{Demand for IUDs and revenue expected from IUDs at the Patte d'Oie centre}

The maximum prices proposed by IUD clients at the Patte d'Oie centre ranged from \$1 (500 FCFA) to \$20 (10,000 FCFA). Based on responses, only $16 \%$ of clients could support a price of $\$ 10$ (5,000 FCFA), but $68 \%$ could pay as much as $\$ 4$ (2,000 FCFA), with a sharp decline after that amount (Figure 8).
An IUD insertion at the Patte d'Oie centre currently costs \$1 (500 FCFA), which generates an estimated revenue of $\$ 517$ (255,000 FCFA). To maximise revenue, the optimal price should be set at $\$ 4(2,000$ FCFA), which would generate estimated revenue of $\$ 1,420$ (700,000 FCFA). Sixty-eight percent of clients would be willing to pay this revised price.

FIGURE 8: Willingness to pay for IUD at the Patte d'Oie centre

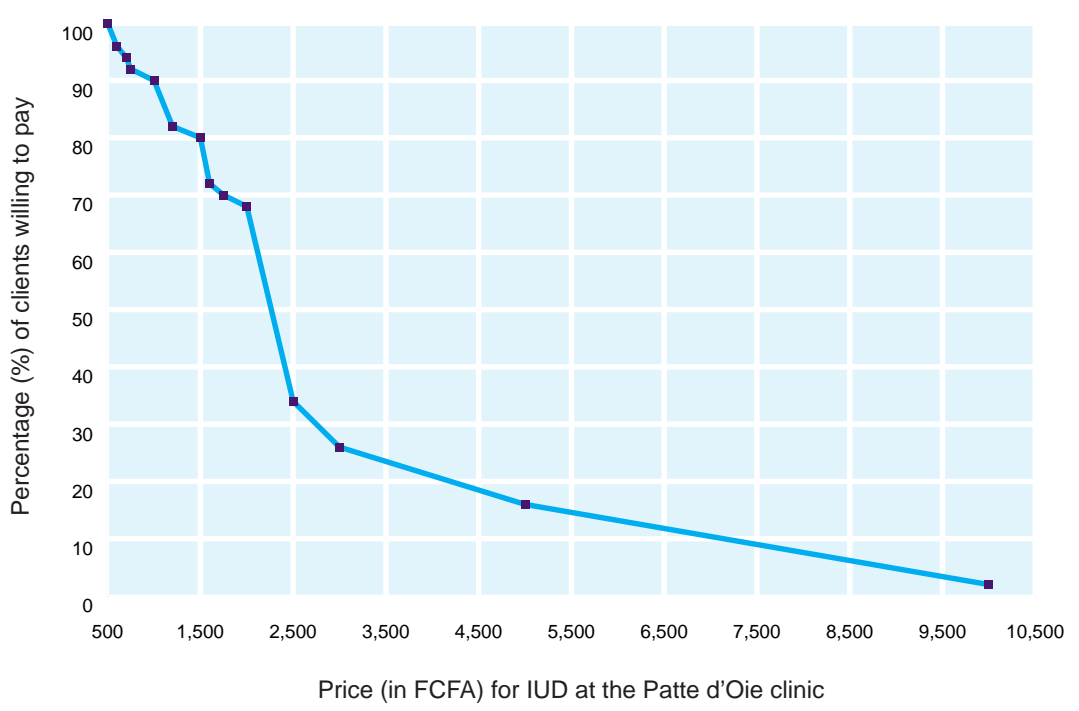

FIGURE 9: Estimation of expected revenue from IUD at the Patte d'Oie centre

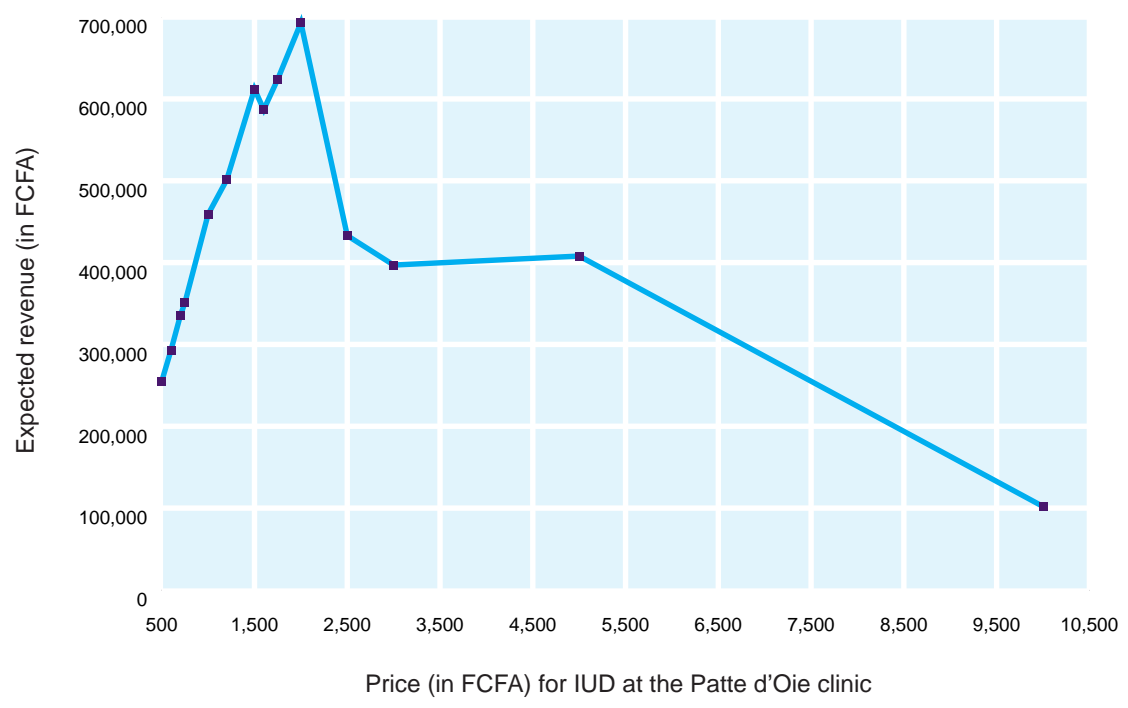




\subsubsection{Demand for IUDs and revenue expected from IUDs in outreach}

At the outreach sites, the maximum prices proposed for IUDs ranged from $\$ 1$ (500 FCFA) to $\$ 10$ (5,000 FCFA) (see Figure 10). The graph shows that $85 \%$ of clients were willing to pay $\$ 2$ (1,000 FCFA), with an estimated $64 \%$ willing to pay $\$ 2.50$ (1,250 FCFA). The proportion declined sharply after $\$ 2$ (1,000 FCFA) and slightly less than $30 \%$ were willing to pay more than $\$ 4$
(2,000 FCFA) for an IUD.

An IUD insertion at outreach sites currently costs \$1 (500 FCFA), which generates estimated revenue of $\$ 7,300$ (3.6 million FCFA). To maximize revenue, the optimal price should be set at \$2 (1,000 FCFA), which would generate estimated revenue of $\$ 12,160$ (6 million FCFA). Eighty-five percent of clients would be willing to pay this revised price.

FIGURE 10: Willingness to pay for IUD at outreach sites

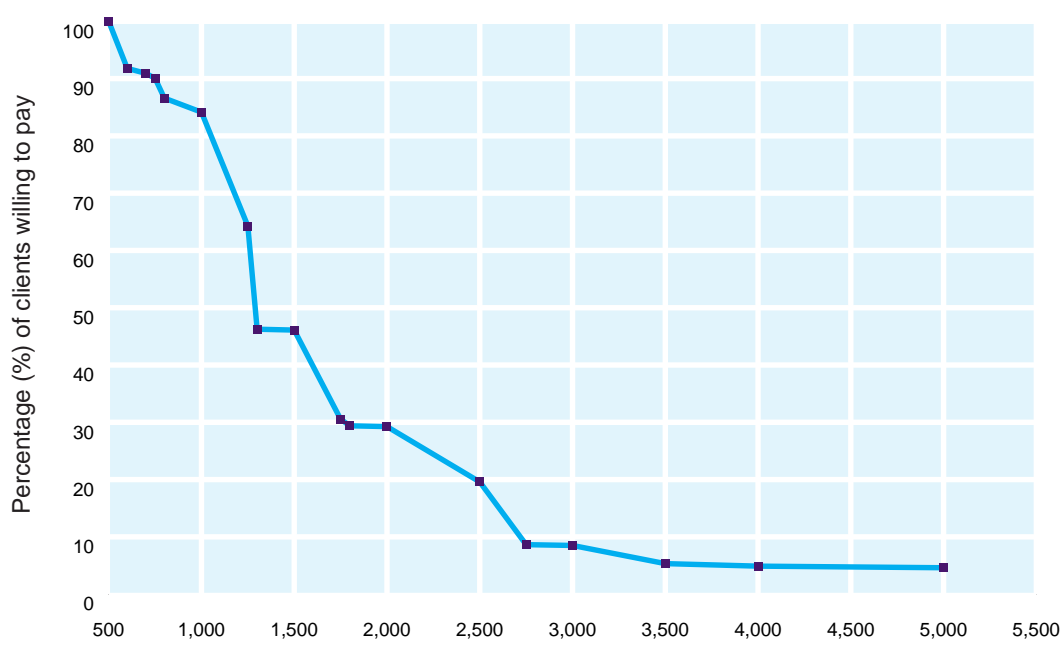

Price (in FCFA) for IUD at outreach sites

FIGURE 11: Estimated revenue from IUD at outreach sites

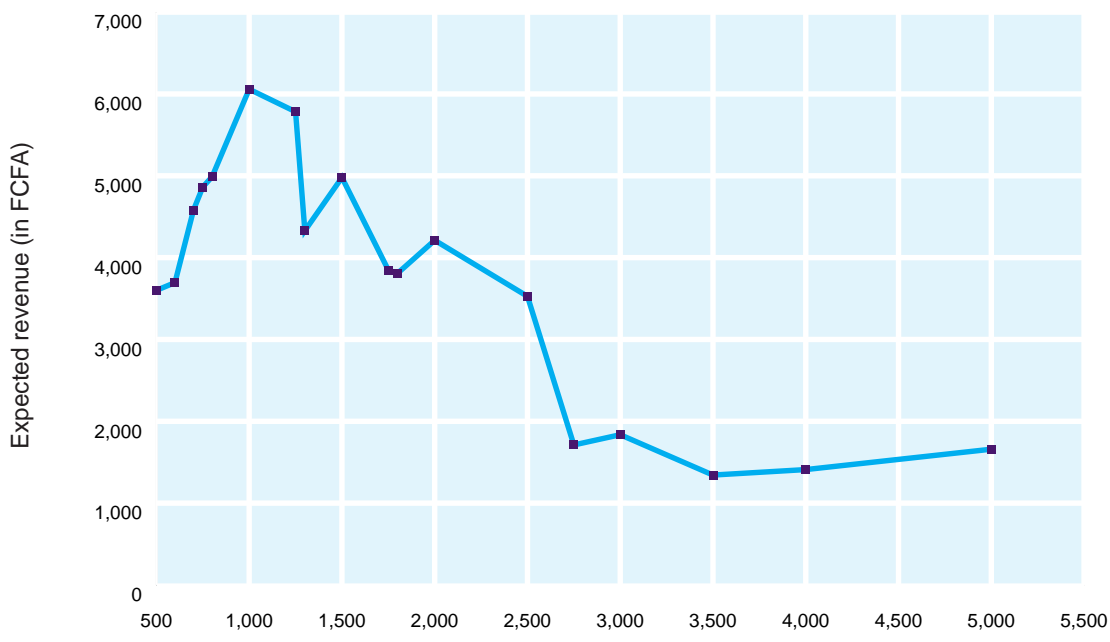

Price (in FCFA) for IUD at outreach sites 


\section{Conclusions and recommendations}

This study's objectives involved:(i) determining clients' socio-demographic characteristics; (ii) estimating clients' levels of satisfaction; (iii) assessing clients' willingness to pay for family planning services; (iv) calculating demand and revenue curves for IUD insertions and contraceptive implants at the Patte d'Oie centre and outreach sites; and (v) estimating maximal price and revenue for selected contraceptive methods.

The study shows that respondents' ages were varied with $30 \%$ of clients between 15 and 24 years of age, $41 \%$ between 25 and 34 years, and $29 \%$ of clients being 35 or older. Most clients were married or living with a partner; $62 \%$ had three or more children, and $17 \%$ had six or more. Most clients had no formal education or had not completed primary schooling, and nearly half were farmers or herders. One-fifth were either unemployed or housewives, and just over one-third lived on less than $\$ 1.25$ per day.

Clients were asked about their satisfaction with various aspects of MSI's services, such as hours of operation, centre cleanliness, waiting times, service costs, service quality, reception, provider discretion, consultation duration and the treatment procedure. In terms of all these identified aspects, more than $90 \%$ of respondents indicated that they were satisfied or very satisfied.
As regards willingness to pay for family planning services, only five percent of respondents opposed any price increase, and only four percent supported the minimum increase proposed, while $80 \%$ supported the highest proposed increment.

Analysis of the demand and revenue curves indicates that the price for various services could be increased. At the Patte d'Oie centre, analysis indicates that new prices could be set at $\$ 5(2,500$ FCFA) for implants and $\$ 4$ (2,000 FCFA) for IUDs. On mobile outreach, prices could be set at $\$ 3(1,500$ FCFA) for implants and $\$ 2$ (1,000 FCFA) for IUDs.

In light of these results we recommend:

\section{At Patte d'Oie centre}

New prices could be set at $\$ 4$ (2,000 FCFA) for IUDs and \$3 (2,500 FCFA) for implants.

\section{At outreach sites}

At outreach sites, prices could be set at $\$ 2(1,000$ FCFA) for IUDs and \$3 (1,500 FCFA) for implants.

TABLE 11: Summary table

$\begin{array}{lllll}\text { Method } & \begin{array}{l}\text { Current } \\ \text { price USD (FCFA) }\end{array} & \begin{array}{l}\text { Proposed } \\ \text { price USD (FCFA) }\end{array} & \begin{array}{l}\% \text { of clients } \\ \text { able to pay }\end{array} & \begin{array}{l}\text { Estimated revenue } \\ \text { USD (FCFA) }\end{array}\end{array}$

\section{Patte d'Oie centre}

$\begin{array}{lllll}\text { IUD } & \$ 1(\text { FCFA 500) } & \$ 4(\text { FCFA 2,000) } & 68 & \$ 1,420(700,000) \\ \text { Implant } & \$ 4(\text { FCFA 2,000) } & \$ 5(\text { FCFA 2,500) } & 90 & \$ 4,460(2.2 \text { million) }\end{array}$

\section{Outreach sites}

IUD

Implant
$\$ 1$ (FCFA 500)

$\$ 1.20$ (FCFA600)
$\$ 2$ (FCFA 1,000)

85

\$3 (FCFA 1,500)
$\$ 12,170$ (6 million)

$\$ 15,820$ (7.8 million) 
The experience in Burkina Faso provides important lessons for MSI programmes and other organisations providing reproductive health services:

- WTP is a useful tool to make informed decisions about cost recovery that minimises unacceptable financial burdens on clients but allows a programme to make evidence-based price increases. The survey instrument and methodology proved to be feasible to administer and yielded reliable results for analysis. Others conducting such a survey might wish to add a sample population of non-users from the community to understand how cost is or is not a barrier amongst the population. One limitation of the study is that there is the possibility that some women find MSI's existing prices prohibitive and therefore do not come to the centres for family planning, therefore excluding them from the study by default. The implication of adding the non-users to the survey is that cost, time and logistics will need to be added to the methodology.

- Decisions regarding price changes might depend on the mode of service delivery and the different populations served; mobile outreach clients and those attending centres do vary. In particular, poverty rates are significantly higher among outreach clients. This has important implications not only for pricing but can depend on whether the primary goal of the service delivery channel is reaching the underserved and poor, or sustainability and cost recovery.
Mobile outreach is an important part of MSI's services in many countries. In 2011, almost two-thirds (64\%) of 2.17 million LAPMs provided by MSI in 38 countries were delivered by clinical mobile outreach. As mobile outreach is likely to continue to be a major part of MSI services, what are the cost and sustainability issues to consider? WTP studies could be useful in supporting programmes to consider testing price changes in some pilot sites to see if it is feasible.

- It is important to monitor service use when instituting any price changes to determine whether any increases posed a barrier for clients. This should be done before and after price changes to note any changes.

- In conjunction with using WTP studies for price setting programmes, MSI should use its costing tools to understand the real costs for providing services when attempting to recover costs and add to programme sustainability.

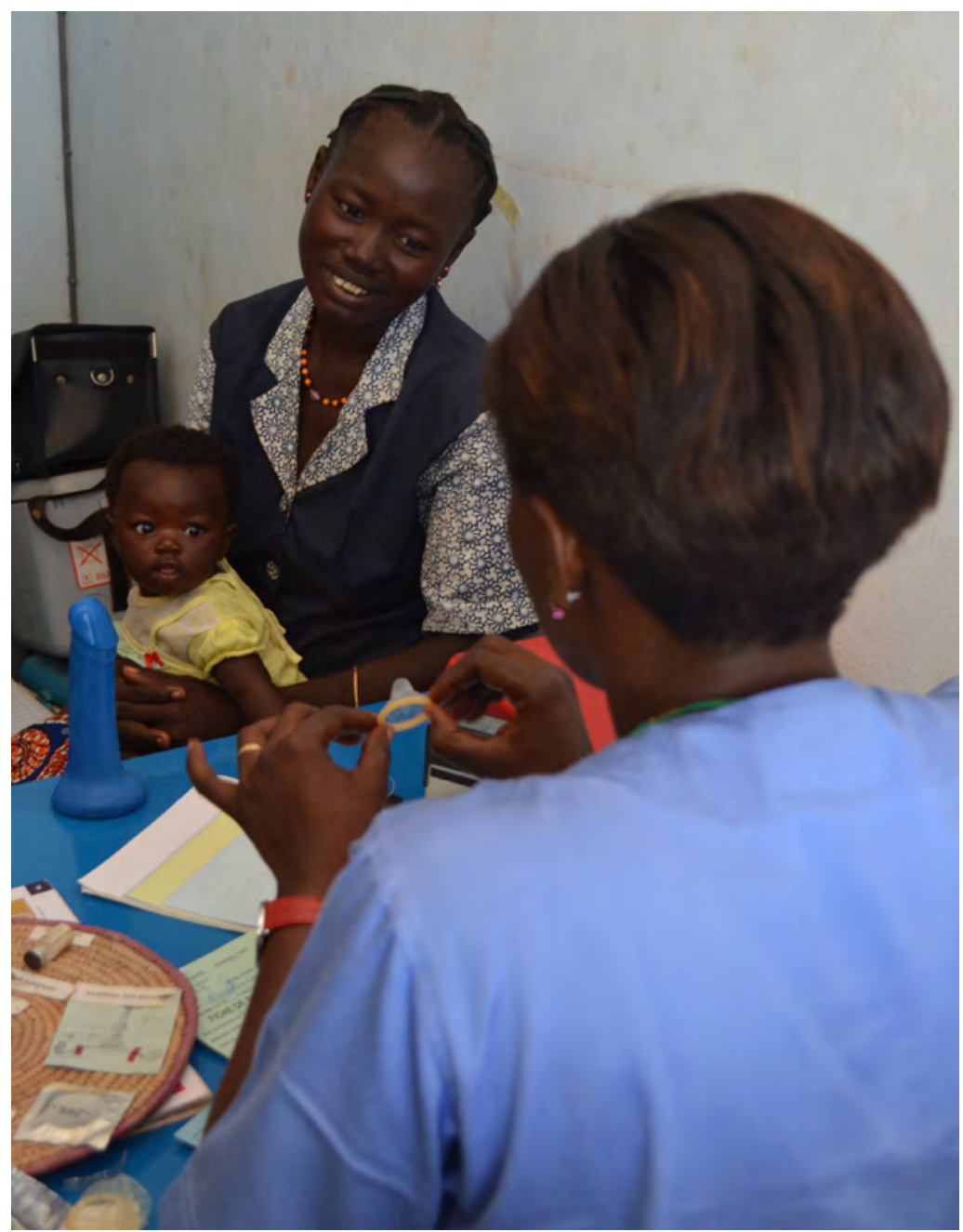


For Marie Stopes International Burkina Faso, the process of implementing the WTP survey was insightful, providing evidence on client satisfaction with services and willingness to contribute the cost of receiving their implant or IUD. With the evidence generated from the survey, MSI BF weighed the objectives of reaching the highest need clients while at the same time generating revenue for sustainability and subsidies. Consideration of these objectives resulted in the decision to increase prices for implants and IUDs but only to the level that $90 \%$ of clients would accept.

Only minimal price increases were made on mobile outreach, given that the main goal of this service delivery channel is to reach underserved populations. Additionally, the increase in revenue that could be potentially generated would still not cover a substantial portion of the programme costs, thus risking loss of clients without concomitant increases in sustainability. To this end, MSI BF chose to set a threshold of $90 \%$ of clients who said they would be willing to pay for services at the centre.
This decision-making process shows the challenges of applying research findings and the reality of the types of decisions that such programmes may need to take to consider other factors when providing services.

Implementing the WTP survey allowed the programme to make decisions based on real client data and information, collected in a reliable and consistent way, and to analyse pricing based on evidence, while also taking into account other factors including organisational aims and goals.

\begin{tabular}{|c|c|c|c|c|c|}
\hline $\begin{array}{l}\text { Patte d'Oie } \\
\text { centre }\end{array}$ & $\begin{array}{l}\text { Price at time of } \\
\text { study USD } \\
\text { (FCFA) }\end{array}$ & $\begin{array}{l}\text { Revised price } \\
\text { USD (FCFA) }\end{array}$ & $\begin{array}{l}\% \text { of clients } \\
\text { willing to } \\
\text { pay }\end{array}$ & $\begin{array}{l}\text { Projected } \\
\text { revenue at } \\
\text { revised price } \\
\text { USD (FCFA) }\end{array}$ & $\begin{array}{l}\text { Projected } \\
\text { revenue at } \\
\text { current price } \\
\text { USD (FCFA) }\end{array}$ \\
\hline Implants & $\begin{array}{l}\$ 4 \\
(2,000 \text { FCFA })\end{array}$ & $\begin{array}{l}\$ 5 \\
(2,500 \text { FCFA })\end{array}$ & $90 \%$ & $\begin{array}{l}\$ 4,460 \\
(2.2 \text { million })\end{array}$ & $\begin{array}{l}\$ 3,850 \\
(1.9 \text { million })\end{array}$ \\
\hline IUD & $\begin{array}{l}\$ 1 \\
(500 \text { FCFA) }\end{array}$ & $\begin{array}{l}\$ 2 \\
(1,000 \text { FCFA })\end{array}$ & $90 \%$ & $\begin{array}{l}\$ 912 \\
(450,000)\end{array}$ & $\begin{array}{l}\$ 517 \\
(255,000)\end{array}$ \\
\hline
\end{tabular}

\begin{tabular}{|llllll|}
\hline Outreach sites & $\begin{array}{l}\text { Price at time of } \\
\text { study }\end{array}$ & Revised price & $\begin{array}{l}\text { \% of clients } \\
\text { able to pay }\end{array}$ & $\begin{array}{l}\text { Revenue at } \\
\text { revised price } \\
\text { (CFA) }\end{array}$ & $\begin{array}{l}\text { Revenue at } \\
\text { former price } \\
\text { (CFA) }\end{array}$ \\
\hline Implants & 600 CFA & 750 CFA & $93 \%$ & $5.7 m$ & $5 m$ \\
\hline IUD & 500 CFA & 750 CFA & $90 \%$ & $5 m$ & $3.6 m$ \\
\hline TL & 500 CFA & 750 CFA & $93 \%$ & $1 m$ & 720.000 \\
\hline
\end{tabular}




\section{References}

1 USD \$1 = FCFA 495. Exchange rate September 2013

2 Franc de la Communauté Financière d'Afrique (West African CFA Franc). 1 Euro = 656 FCFA

3 The Ministry of Health homogenised prices to include all costs related to delivery of FP services across health facilities in 2011 . However, in some instances clients continued to face additional charges for consumables such as gloves, gauze, etc.

4 Foreit JR. and Fleischman Foreit KG. The reliability and validity of willingness to pay surveys for reproductive health pricing decisions in developing countries. Health Policy 2003;63;37-47.

5 Foreit JR. and Fleischman Foreit KG. Willingness to pay surveys for setting prices for reproductive health products and services: A user's manual. Population Council, 2004.

6 Exit interviews include ten questions which estimate the likelihood that a household has expenditure below a given poverty line based on Burkina Faso's 2003 Household Living Standards Survey (EBCVM, Enquête Burkinabé sur les Conditions de Vie des Ménages, 2003).

7 Only 171 of the initial respondents at the centre answered questions on willingness to pay.

\section{Bibliography}

Bahan D. and Kabore I. Pratique contraceptive par les femmes en union au Burkina Faso: Quelle est la place et le rôle du conjoint?, Communication presented at the sixth UEPA conference, December 2011 (17 pages).

Congo Z. Les facteurs de la contraception au Burkina Faso, 2005, 53 p.

Institut National de la Statistique et de la Démographie et Orc Macro. Rapport préliminaire de l'enquête démographique et de santé du Burkina Faso 2010. Calverton, Maryland: INSD et ORC Macro, 2011 (50 pages).

Institut National de la Statistique et de la Démographie. Etat matrimonial et nuptialité, Rapport d'analyse du recensement général de la population et de l'habitation de 2006, 2009 (196 pages).

Institut National de la Statistique et de la Démographie et Orc Macro. Enquête démographique et de santé du Burkina Faso 2003. Calverton, Maryland: INSD et ORC Macro, 2004 (455 pages).

Foreit JR. and Fleischman Foreit KG. Willingness to pay surveys for setting prices for reproductive health products and services: A user's manual.. [Manuel de l'utilisateur des enquêtes d'acceptation de paiement destinées à déterminer les prix des produits et services dans le domaine de la santé de la reproduction.] Population Council, 2004 (34 pages).

Foreit JR. and Fleischman Foreit KG. The reliability and validity of willingness to pay surveys for reproductive health pricing decisions in developing countries. Health Policy 2003;63;37-47.

Marie Stopes International. Guidelines for implementing the MSI Client Satisfaction Exit Interviews for Marie Stopes International Partners. Marie Stopes International, 2011.

Schreiner M. A Simple Poverty Scorecard for Burkina Faso 2011. This document is available at http://www. microfinance.com/\#Burkina_Faso. 
Marie Stopes International

1 Conway Street

Fitzroy Square

London W1T 6LP

$\mathrm{t}:+44(0) 2076366200$

f: +44 (0)20 70342369

e: info@mariestopes.org

w: www.mariestopes.org

Registered charity number: 265543

Company number: 1102208
Population Council

One Dag Hammarskjold Plaza

9th Floor

New York, NY 10017

USA

t: +1 2123390500 